\title{
Type III pleuropulmonary blastoma in a 7-month-old female baby with impending respiratory failure: a case report
}

\author{
Agnese Castro ${ }^{1}$, Chiara Franzonello ${ }^{1}$, Salvatore Leonardi ${ }^{1}$, Andrea Di Cataldo ${ }^{1}$, Enrico Potenza ${ }^{2}$, Gaetano Magro ${ }^{3}$, \\ Giovanni A Rossi ${ }^{4}$ and Mario La Rosa ${ }^{1 *}$
}

\begin{abstract}
Introduction: Pleuropulmonary blastoma is a very rare, aggressive, embryonal pulmonary neoplasm which mostly affects children under the age of 5. According to the histopathological features, three subtypes of pleuropulmonary blastoma have been recognized: type I (purely cystic), type II (grossly visible cystic and solid elements) and type III (purely solid). Characteristics of type I and type II blastoma allow an earlier diagnosis compared with type III. Here we present a case report of an unusual presentation of type III pleuropulmonary blastoma.

Case presentation: We describe the case of a 7-month-old female baby of Italian mother and Kurdish father who was diagnosed with type III pleuropulmonary blastoma, which entirely occupied her right hemithorax.

Conclusions: The reported case is an unusual presentation because type III pleuropulmonary blastoma typically occurs in older children. The complete re-expansion of her residual, previously totally compressed, right lung observed immediately after the resection of the lesion suggests an atypical rapid growth of this embryonal tumor in the late phase of gestation or after delivery. This case report suggests that, in addition to other childhood tumors, type III pleuropulmonary blastoma should be included in the differential diagnosis of solid nonhomogeneous thoracic large masses, compressing the mediastinal and chest wall structures in infants. This is an original case report of interest for several specialities such us pediatrics, radiology, surgery and oncology.
\end{abstract}

Keywords: Pediatric tumors, Respiratory failure, Thoracic CT scan

\section{Introduction}

Pleuropulmonary blastoma $(\mathrm{PPB})$ is a rare malignant embryonal tumor of the lungs that appears to arise during organ development and is usually diagnosed in the pediatric population under the age of $5[1,2]$. The formation of the tumor seems to begin as air-filled cysts with primitive mesenchymal cells beneath an intact benign-appearing epithelium (type I PPB). In the following stages, the mesenchymal cells overgrow the delicate septa producing a cystic and solid or exclusively solid sarcomatous neoplasm (types II and III PPB, respectively) [1-5]. The progression from type I to type II or type III PPB has been pathologically documented and observed in children diagnosed with type II or type III

\footnotetext{
* Correspondence: m.larosa@unict.it

'Department of Pediatrics, University of Catania, Catania, Italy

Full list of author information is available at the end of the article
}

PPB who had chest radiographs showing lung cysts preceding the diagnosis of PPB [3-8]. The evolution from a relatively simple multicystic neoplasm, characterized by a restricted population of cells with rhabdomyoblastic differentiation, to a large solid neoplasm filling the thoracic cavity is reflective of a natural biological progression and explains the correlation between the pathological type with both age at the diagnosis and patient outcome [1,4]. Indeed, type I PPB is detected in infants (median diagnosis age, 9 to 10 months) and has a favorable prognosis with 85 to $90 \%$ overall survival $[3,4]$. In contrast, the more aggressive types II and III PPB are typically diagnosed in older children (median diagnosis ages, 34 to 36 and 42 to 44 months, respectively) $[1,3,4]$ and have an overall survival estimates of $60 \%$ and $45 \%$, respectively [1,4]. Distant metastases seem to occur only in type II or type III PPB, affecting the brain/spinal cord or bone [1,9]. 
Since type I PPB may recur after treatment as a type II or type III PPB and has a low recovery rate, it is vital to diagnose and treat the affected children at an early stage (type I PPB) and age, when the lesion is limited and most curable $[1,4]$. Unfortunately, as the initial presentation can be subtle, being characterized by a series of recurrent respiratory tract infections associated with slowly progressive shortness of breath, an early diagnosis is incidental in most cases [1-3]. Here we describe the case of a large type III PPB occupying the whole right hemithorax that had the unusual characteristic of being diagnosed in a 7-month-old female baby who, due to the size of the tumor, was hospitalized because of impending respiratory failure.

\section{Case presentation}

A 7-month-old female baby of Italian mother and Kurdish father was referred to our Pediatric Department for rapidly worsening dyspnea leading to severe shortness of breath. Respiratory symptoms, occurring intermittently in her first 2 to 3 months of life during upper respiratory tract infection, progressively worsened in length and severity and were subsequently associated with anorexia and failure to thrive. On admission, she appeared dyspneic and hypoxic and needed a high-level of oxygen $\left(\mathrm{O}_{2}\right)$ supplementation (an inspired fraction of $\mathrm{O}_{2}=5 \mathrm{~L} /$ minute) to achieve an $\mathrm{O}_{2}$ saturation of $95 \%$. Her blood pressure was $50 / 90 \mathrm{mmHg}$, heart rate 135 beats per minute and body temperature $36.5^{\circ} \mathrm{C}$. An absence of breath sounds in her right hemithorax was perceived during her chest examination. Her white blood cells were $19.23 \times 10^{3} / \mathrm{mm}^{3}$ (neutrophils $62.6 \%$ and lymphocytes $27 \%$ ), hematocrit $34.5 \%$, mean corpuscular hemoglobin concentration $30.7 \mathrm{~g} / \mathrm{dL}$, platelet counts $695 \times 10^{3} / \mathrm{mm}^{3}$, reticulocytes $182 \times 10^{9} / \mathrm{L}$. Values lower than normal levels were detected for total proteins $(5.3 \mathrm{~g} / \mathrm{dL})$, albumin $(2.8 \mathrm{~g} / \mathrm{dL})$, iron $(17 \mu \mathrm{g} / \mathrm{dL})$, immunoglobulin (Ig) A (30mg/dL) and IgG $(625 \mathrm{mg} / \mathrm{dL})$, whereas her erythrocyte sedimentation rate $(44 \mathrm{~mm} /$ hour $)$ and C-reactive protein $(5.05 \mathrm{mg} / \mathrm{dL}$; normal range $<0.80 \mathrm{mg} / \mathrm{dL})$ were elevated.
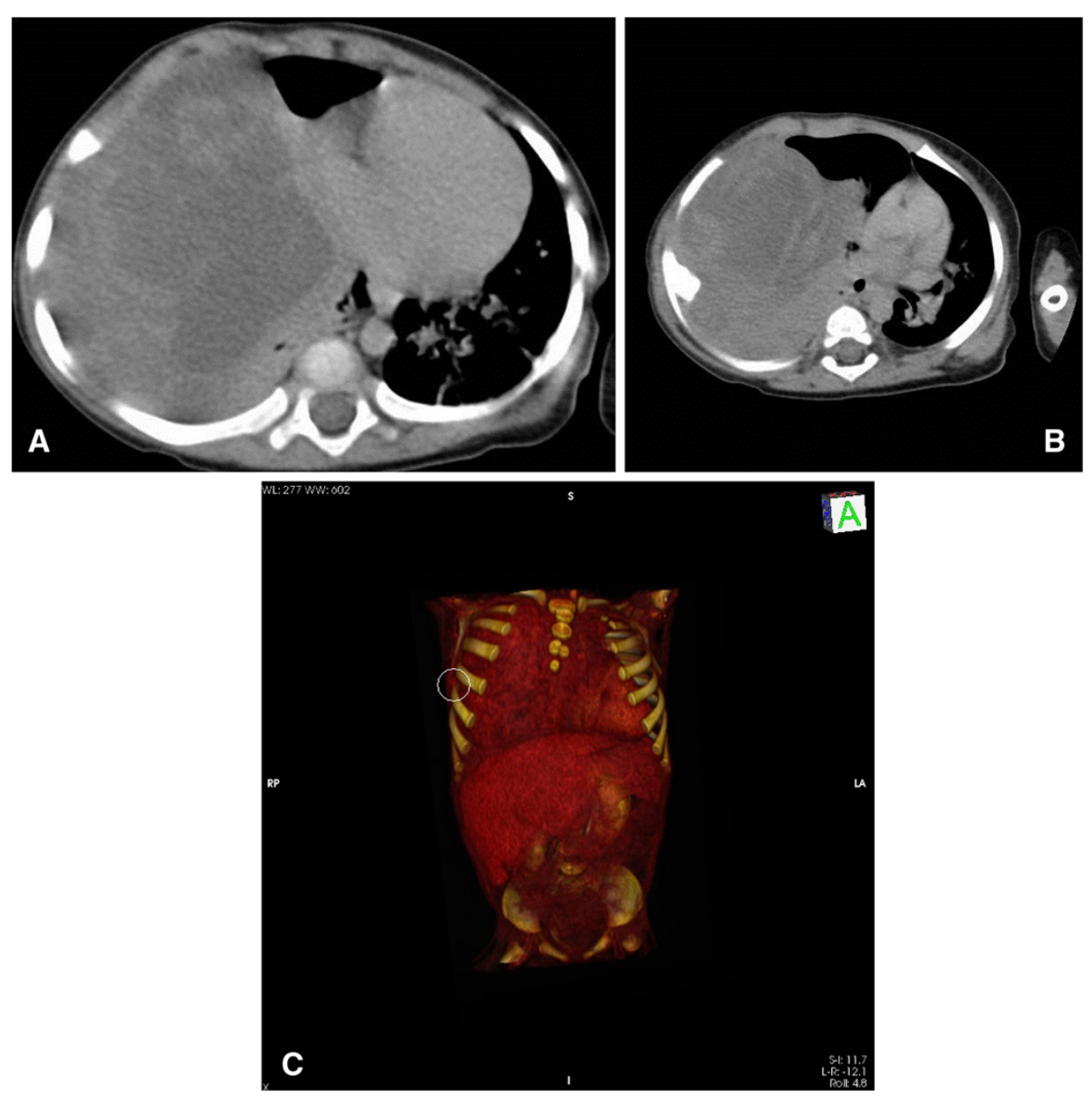

Figure 1 Computed tomography scanning of the thorax. Demonstrating the presence of an enormous mass, causing a tracheal displacement with complete collapse of the lung parenchyma (A) with structural alteration in the 6th right coastal arc, along the midaxillary line (B) better demonstrated by the three-dimensional reconstruction (C). 


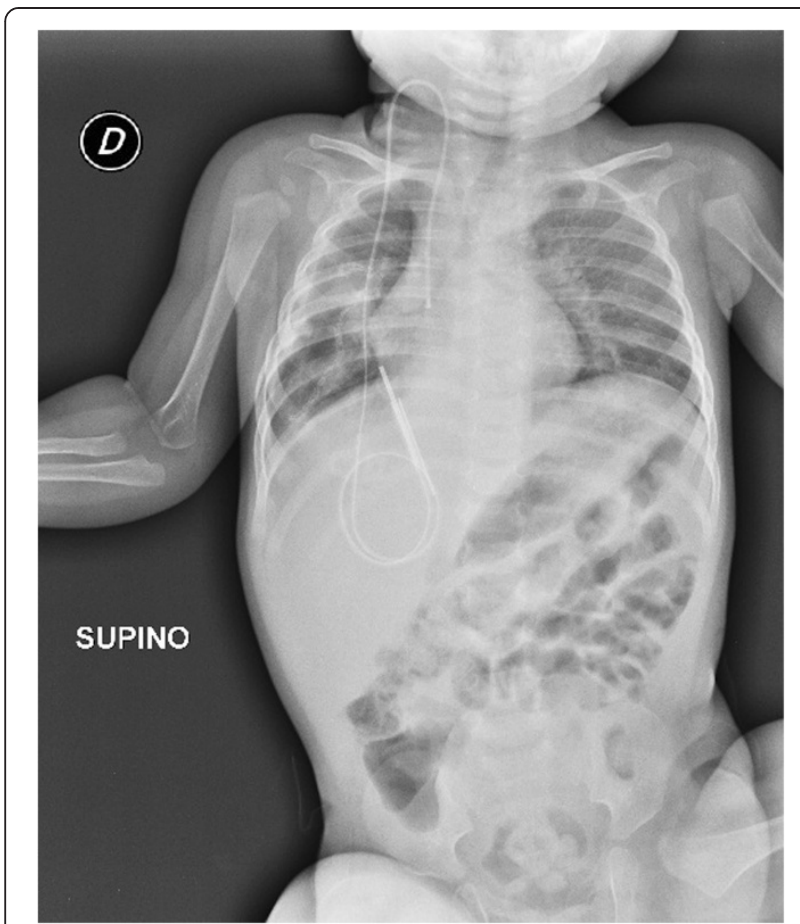

Figure 2 Chest radiography after the surgical removal of the intrathoracic tumor demonstrating a complete re-expansion of the right lung.

Conventional chest radiography demonstrated a complete opacification of her right hemithorax with contralateral midline shift. Computed tomography (CT) scanning was performed and showed the presence of an enormous mass resulting in the contralateral displacement of her trachea, with total collapse of right lung parenchyma (Figure 1A) and compression of her chest wall tissues, causing a structural alteration of her 6th right costal arc along the midaxillary line (Figures $1 \mathrm{~B}$ and $1 \mathrm{C}$ ). Furthermore, enlarged lymph nodes were detected in both in her mediastinum and her right axillary region. A surgical complete resection of the mass was performed by sternotomy, which resulted in the re-expansion of her right lung, previously compressed and crouched on her mediastinum (Figure 2). The parietal pleura and her anterior mediastinum were not involved and no pleural effusion was detected. The tumor appeared to be a solid greyish-white mass, $8.5 \times 9 \times 5 \mathrm{~cm}$ in size, partially covered by a thin capsule with hemorrhagic areas below. On histological examination, there was a myxoid and fibrous-like stroma showing large areas of necrosis (Figure 3A). At higher magnification the tumor was constituted by blastomatous areas (containing epithelioid cells) and sarcomatous areas (containing fusiform cells; Figure $3 \mathrm{~B}$ ). The growing pattern was fibrosarcomatous dermatofibrosarcoma protuberans-like, with a high mitotic count (30/10 high-power field) and diffused positivity for vimentin; heterogeneous positivity for S-100 protein and focal positivity for CD56 were noticed. The morphological and immunohistochemical features of the resected mass suggested the diagnosis of PPB type III. Brain magnetic resonance imaging, liver CT and skeletal scintigraphy did not reveal any secondary localization. She received adjuvant chemotherapy, which included an intensive combined therapy of ifosfamide, vincristine, actinomycin D and doxorubicin for 25 weeks (IVADo). Due to the radical resection and the absence of metastasis, postoperative irradiation was not performed.

\section{Conclusions}

The occurrence of a type III PPB occupying the whole right hemithorax in a 7-month-old female baby is an unusual finding, suggesting an atypical rapid progression of this embryonal tumor in the late phase of gestation or after delivery. In our patient, nonspecific symptoms such as cough and mild dyspnea were noticed during infectious processes of the respiratory tract occurring 4 to 5 months before the final diagnosis. These symptoms rapidly
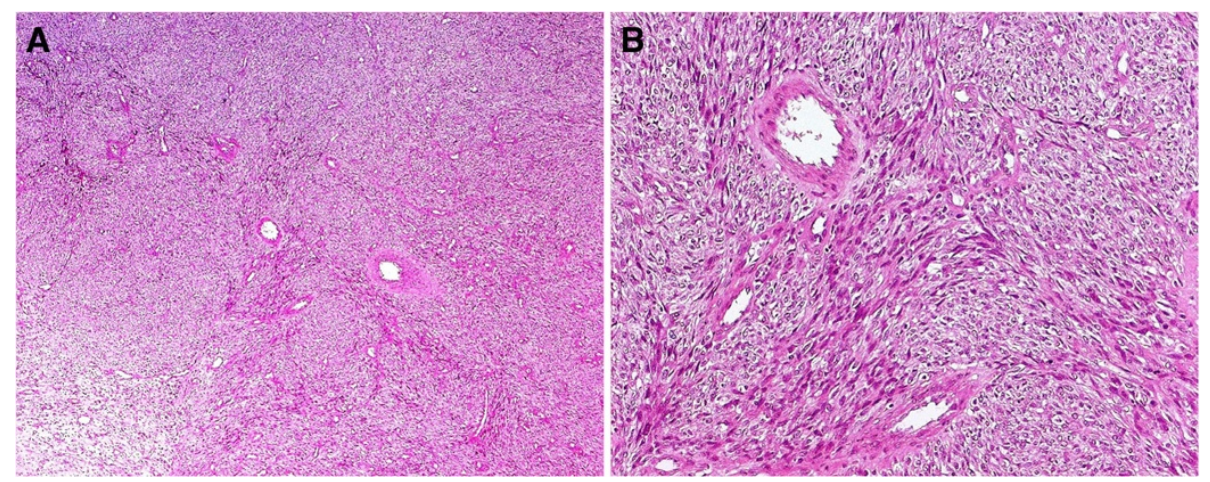

Figure 3 Light microscopy picture of a specimen of the resected mass. A: the tumor is characterized by myxoid and fibrous-like stroma, showing large areas of necrosis (hematoxylin and eosin staining, original magnification $\times 100$ ). B: at higher magnification the tumor was constituted by blastomatous areas, containing epithelioid cells, and sarcomatous areas, containing fusiform cells (hematoxylin and eosin staining, original magnification $\times 250$ ). 
worsened leading to respiratory failure. Presurgical imaging techniques clarified the features and the extension of the mass yet the specific diagnosis was based on histological examination. The radical resection of the mass and the absence of metastasis are favorable prognostic factors. Indeed, in addition to the histological type, the survival rate depends on the local recurrence and the risk of secondary localization in the lungs, thoracic structures, brain or spinal cord [8]. From a clinical prospective, the present case report indicates that, in addition to other childhood tumors such as rhabdomyosarcoma, neuroblastoma and Ewing's sarcoma tumors family, type III PPB should be included in the differential diagnosis of solid nonhomogeneous thoracic large masses, compressing the mediastinal and chest wall structures also in infants $[1,3-6,8-10]$.

\section{Consent}

Written informed consent was obtained from the parents of the patient for publication of this case report and any accompanying images. A copy of the written consent is available for review by the Editor-in-Chief of this journal.

\section{Abbreviations}

CT: Computed tomography; $\mathrm{O}_{2}$ : Oxygen; PPB: Pleuropulmonary blastoma; IgA: Immunoglobulin A; IgG: Immunoglobulin G; CD56: Cluster of differentiation 56; IVADo: Ifosfamide, vincristine, actinomycin D and doxorubicin;

3D: Three dimensional.

\section{Competing interests}

All authors declare that they have no competing interests.

\section{Authors' contributions}

ADC, EP, GM contributed to acquisition of data. AC, CF, SL, GAR and MLR drafted the report and all authors contributed to revision of the report. All authors read and approved the final manuscript.

\section{Acknowledgements}

The authors have no disclosures to make and have had no source of funding in the preparation of this manuscript. We would like to thank Dr Andrea Praticò for his technical support.

\section{Author details}

${ }^{1}$ Department of Pediatrics, University of Catania, Catania, Italy. ${ }^{2}$ Operating Unit of Thoracic Surgery, Garibaldi-Nesima Hospital, Catania, Italy. ${ }^{3}$ Section of Anatomic Pathology, Department G.F. Ingrassia, University of Catania, Catania, Italy. ${ }^{4}$ Pediatric Pulmonology and Allergy Unit, Institute of Giannina Gaslini, Genoa, Italy.

Received: 29 December 2013 Accepted: 7 April 2014

Published: 23 June 2014

\section{References}

1. Priest JR, McDermott MB, Bhatia S, Watterson J, Manivel JC, Dehner LP: Pleuropulmonary blastoma: a clinicopathologic study of 50 cases. Cancer 1997, 80:147-161.

2. Piastra M, Ruggiero A, Caresta E, Granone P, Chiaretti A, Polidori G, Riccardi R: Critical presentation of pleuropulmonary blastoma. Pediatr Surg Int 2005, 21:223-226

3. Priest JR, Hill DA, Williams GM, Moertel $C L$, Messinger $Y$, Finkelstein $M J$, Dehner LP: Type I pleuropulmonary blastoma: a report from the International Pleuropulmonary Blastoma Registry. J Clin Oncol 2006, 24:4492-4498.
4. Hill DA, Jarzembowski JA, Priest JR, Williams $G$, Schoettler $P$, Dehner LP: Type I pleuropulmonary blastoma: pathology and biology study of 51 cases from the international pleuropulmonary blastoma registry. Am J Surg Pathol 2008, 32:282-295.

5. Perdikogianni C, Stiakiki E, Danilatou V, Delides G, Kalmanti M: Pleuropulmonary blastoma: an aggressive intrathoracic neoplasm of childhood. Pediatr Hematol Oncol 2001, 18:259-266.

6. Dehner LP, Watterson J, Priest J: Pleuropulmonary blastoma. A unique intrathoracic-pulmonary neoplasm of childhood. Perspect Pediatr Pathol 1995, 18:214-226

7. Orazi C, Inserra A, Schingo PM, De Sio L, Cutrera R, Boldrini R, Malena S: Pleuropulmonary blastoma, a distinctive neoplasm of childhood: report of three cases. Pediatr Radiol 2007, 37:337-344.

8. Dehner LP: Beware of "degenerating" congenital pulmonary cysts. Pediatr Surg Int 2005, 21:123-124.

9. Indolfi P, Bisogno G, Casale F, Cecchetto G, De Salvo G, Ferrari A, Donfrancesco A, Donofrio V, Martone A, Di Martino M, Di Tullio MT: Prognostic factors in pleuro-pulmonary blastoma. Pediatr Blood Cancer 2007, 48:318-323.

10. Geiger J, Walter K, Uhl M, Bley TA, Jüttner E, Brink I, Kirschbaum A, Kontny U: Imaging findings in a 3-year-old girl with type III pleuropulmonary blastoma. In Vivo 2007, 21:1119-1122.

doi:10.1186/1752-1947-8-221

Cite this article as: Castro et al:: Type III pleuropulmonary blastoma in a 7-month-old female baby with impending respiratory failure: a case report. Journal of Medical Case Reports 2014 8:221.

\section{Submit your next manuscript to BioMed Central and take full advantage of:}

- Convenient online submission

- Thorough peer review

- No space constraints or color figure charges

- Immediate publication on acceptance

- Inclusion in PubMed, CAS, Scopus and Google Scholar

- Research which is freely available for redistribution 